\title{
PREGNANCY AND RHEUMATIC HEART DISEASE
}

\author{
By Samuel Oram, M.D., F.R.C.P. \\ Physician, King's College Hospital; Cardiologist, Croydon Group of Hospitals
}

There is no doubt that of all branches of cardiology the effect of pregnancy upon rheumatic heart disease is the one concerning which there is most discrepancy in the literature. There are several reasons for this difference of opinion among cardiologists, the chief of which are our incomplete knowledge of the effect of pregnancy on the normal heart, the difficulty in distinguishing cardiovascular signs resulting from normal pregnancy from those due to early cardiac disease, and the fact that abnormal physical signs are prone to become either more or less obvious as pregnancy progresses. In addition, other inherent difficulties are encountered as soon as one attempts to study the effect of pregnancy on the diseased heart. The most serious source of error is the tendency for authors to deduce too much from too few cases, and the number of clinics in this country devoted mainly to the study of the pregnant woman with heart disease can be counted on the fingers of one hand. Too rarely is the aid of the statistician sought. Even where large series of cases are summated (Julius Jensen, I938), too often the criteria used by various authors in their diagnoses are slightly different, and for this reason their results are not strictly comparable. Another difficulty arises from the different way in which the cardiologist and the obstetrician regard the problem. The cardiologist considers the pregnancy as complicating the pre-existing heart disease, but the obstetrician considers that his patient's pregnancy is complicated by her cardiac lesion. Another cause for ignorance is that the obstetrician rarely studies his patients once the puerperium has been successfully passed, and if further pregnancies do not ensue he may never see the patient again. On the other hand, the cardiologist rarely follows the same patient through several pregnancies unless he is particularly interested in the subject, and his opportunities for observing closely the heart in normal pregnancy are few. When one tries to assemble a comparable series so many variables are discovered that the effect of any single one acting alone is virtually imponderable-for example, the increasing age of $\bar{\omega}$ the mother with successive pregnancies, the time $\overrightarrow{0}$ interval between pregnancies and the medical and 3 . domestic facilities available before, during and after delivery. Even religious principles are apt to $\stackrel{N}{\omega}$ influence treatment.

However, in spite of the extent of the problem, of recent years ideas are gradually becoming 0 crystallized particularly as a result of increasing knowledge of the physiology of the circulation $\vec{T}$ during normal and abnormal pregnancy.

\section{Circulatory Effects of Pregnancy}

All investigators agree that the work of the heart is increased during pregnancy and there 10 also agreement that this is never so great as t. cause failure in the healthy heart. Only the previously diseased heart fails in pregnancy. In fact, it is unlikely that pregnancy by itself can induce failure in a patient with heart disease when signs of failure are absent at the commencement of $\stackrel{\mathbb{Q}}{\Omega}$ cyesis and when the severity of the heart lesion is $\overrightarrow{\overrightarrow{0}}$ not such as to give rise to failure in a short time in the absence of pregnancy (Evans, 1948).

Provided the cardiac output is moderate the work performed by the heart may, for clinical purposes, be taken as roughly proportional to the cardiac output multiplied by the blood pressure. In normal pregnancy the blood pressure changes are slight, but the cardiac output rises considerably until round about the $34^{\text {th }}$ to 36 th week, after which time it falls. Cohen and Thomson (1936, ㄱ 1939) were the first to show this and until their $\frac{7}{0}$ work it was believed that the cardiac burden became maximal only at term. This increase in $N$ cardiac output is due to increased volume of circulating blood and both plasma and total blood $N$ volume are increased. Thomson et al. (1938) have shown that the plasma volume increases progressively until the ninth lunar month. They found an average increase of 65 per cent. over the average normal non-pregnant value. During the? tenth lunar month there is a definite decrease, the plasma volume falling by this time to some 50 
per cent. above normal. The same workers showed that the total blood volume shows similar changes, increasing by the ninth lunar month to an average of 45.5 per cent. above normal and falling by the tenth month to 32.4 per cent. above normal. The total blood cell volume shows slighter changes but they are of a similar trend. This water retention in both blood and tissues during pregnancy could be accounted for by the considerable salt retention which Chesley (1944) has found to occur during gestation. From about the $34^{\text {th }}$ to 36 th week onwards the cardiac output decreases and rapidly falls after delivery to reach the normal after the first week or two of the puerperium. The average increase in cardiac output is, according to Stander and Cadden (1932), 40 to 50 per cent. of the nonpregnant output. This increase in cardiac output can be achieved by either an increase in stroke volume or in heart rate or both. As the increase in stroke volume is less than the increase in minute volume there must also be an increase in heart rate in pregnancy. Although the increase in cardiac output enables augmentation in blood flow through the uterus without depletion of the other organs, the exact mechanism responsible for the increase in output is still not clear. Burwell (1938) has found that the increase is greater than can be accounted for by the augmented oxygen consumption, for the arteriovenous oxygen difference is decreased. He has advanced the ingenious theory that in pregnancy the placenta, with its wide shunts connecting the arterial and venous sides of the circulation, acts like an arteriovenous fistula, and in support of this is the so-called ' hyperkinetic syndrome' (Harrison, 1935) which is commonly shown during normal pregnancy, namely the vigorous apex beat, loud first sound at the apex, with or without a systolic murmur, flushed skin, collapsing pulse, capillary pulsation, tachycardia, distended cervical and superficial chest and abdominal veins, loud pulmonary second sound and third heart sound. It will be obvious from the above that from the $34^{\text {th }}$ to 36 th week onwards the cardiac status of the pregnant woman is likely to improve. There are, however, other factors which lead either directly or indirectly to an increase in cardiac work, the most important of which is a general increase in body weight. However, this is not such an important factor as has been claimed and even from the i2th week onwards it can be shown that the cardiac output is beginning to increase. Clinically, too, it is well recognized that death of the foetus may greatly relieve the mother's heart failure although the foetus remains in utero.

The dyspnoea of pregnancy is not, as was previously thought, due to a decrease in vital capacity. In fact, Thomson and Cohen (1938) have shown that the vital capacity increases slightly, and this increase may reach some 12 per cent. Although the mechanical effect of the enlarging uterus is to cause a 'splinting' effect on the lower ribs by pressure forwards against the subcostal angle, the actual intrathoracic volume may increase during pregnancy-the subcostal angle progressively increases, the chest circumference increases, the transverse and anteroposterior chest diameters increase and although the long diameter of the chest during quiet respiration is decreased the diaphragm can be seen under the screen to be quite capable of normal exertion. There is no evidence that the diaphragm is pushed upwards by the fundus of the uterus. Dyspnoea depends largely on the ratio between the vital capacity and the pulmonary ventilation. A large increase in pulmonary ventilation with only a relatively slight increase in vital capacity would lead to dyspnoea, and this is precisely what occurs in pregnancy. According to Anthony and Hansen (I933) the pulmonary ventilation in pregnancy increases on the average by 57 per cent. Of course in pregnant patients with heart failure the respiratory reserve is reduced in two ways-by an increase in the resting ventilation due to the pregnancy and a decrease in the vital capacity due to the heart disease.

\section{Assessing the Patient}

As seen by the author the assessment of a pregnant woman suspected of heart disease resolves itself into four separate problems. The first is to establish as early as possible whether heart disease is, in fact, present. If this is confirmed then the second problem is to consider the risks to the patient during pregnancy and soon after. If these risks warrant continuation of the pregnancy, the third question to be decided is the management of the case during pregnancy, labour and puerperium. Finally, after the child has been born, the remote outlook for the mother must be considered before further pregnancies are undertaken.

\section{The Diagnosis of Heart Disease During Pregnancy}

So closely may the signs and symptoms referable to the cardiovascular system during normal pregnancy simulate those arising as a result of cardiac disease that Hamilton and Thomson (194I) have suggested the category of ' possible heart disease' for patients in whom doubt still exists after careful examination. These should be observed closely during pregnancy in exactly the same way as are patients known to have heart disease and they should be delivered in hospital. Fortunately the majority of pregnant women referred to the 
cardiologist for opinion concerning the possibility of heart disease have healthy hearts.

Marshall (1949) has shown that only some 40 per cent. of pregnant women with heart disease have symptoms before pregnancy and some may have up to five children before any symptoms of their heart disease appear.

Of 485 pregnant women with heart disease studied by Morgan Jones (195I).90 per cent. had rheumatic heart disease.

Dyspnoea. Normal pregnancy can give rise to increasing dyspnoea on effort and later even to orthopnoea because of the increase in pulmonary ventilation. Towards the sixth month of pregnancy slight exertional dyspnoea is the rule, but it never becomes such that the woman is unable to attend to her housework. On the other hand some patients with damaged hearts can walk long distances without respiratory distress. Dyspnoea of any extent appearing before the sixth month should raise a suspicion that a pathological lesion is responsible for it although not necessasily cardiac. In a multipara the story that the breathlessness is much worse than in previous pregnancies is ominous if other causes of dyspnoea which can also be effective in the non-pregnant are excluded, and mechanical causes associated with the pregnancy, such as hydramnios or twins, can be ruled out. A syndrome that is little known and was first described by Hamilton and Thomson (I94I) is that of 'pseudo-paroxysmal nocturnal dyspnoea.' These patients are awakened by attacks of choking with respiratory distress and palpitation, and the picture can closely simulate that of failure of the left ventricle, although the prognosis is excellent.

According to Thomson and Cohen (1938) a decrease of vital capacity of i 5 per cent. or more, or a continued decrease from month to month of ro per cent. or more, is a sign of impending heart failure in the pregnant patient with a cardiac lesion.

Oedema. Swelling of the ankles is so common in pregnancy, particularly towards the end, that it is only of value as evidence of heart disease if other signs are present. If the oedema is more than a trace then, if it is due to heart failure, obviously abnormal physical signs will be found in the heart. Slight oedema of the ankles in early pregnancy is probably due to the fluid retention which takes place, perhaps combined with excessive standing, and this is usually most noticeable in hot weather. The oedema may be contributed to in pregnancy by varicose veins, anaemia or flat feet. A trace of oedema of the hands and face can occur in normal pregnancy.

Basal crepitations. The presence of moist sounds at the lung bases is of extreme importance.
They should be diligently searched for at every visit. They are not uncommon in normal pregnancy especially at the right base, but if they do not disappear after a few deep breaths, or a cough or two, they must be regarded as a sign of pul-

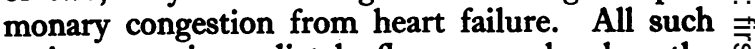
patients are immediately fluoroscoped, when the 0 typical hilar congestion or, sometimes ' groundglass' appearance of pulmonary oedema will be seen.

Distension of the cervical veins. Mackenzie himself (1921) first drew attention to the frequency of jugular vein pulsation during healthy pregnancy. Causation still remains obscure.

Cyanosis. This never occurs during normal pregnancy, although many subjects do develop duskiness of the face and dark red lips during the second stage of labour.

Hepatic engorgement. Unfortunately, the en- N larged uterus during the later months is apt to render palpation of the liver difficult, but the liver is never enlarged or tender as a result of normal o pregnancy, and when present is a valuable sign of $\bigcirc$ early failure of the right side of the heart.

Haemoptysis. The respiratory embarrassment of normal pregnancy never gives rise to blood spitting. All 2 I examples of haemoptysis during pregnancy were found by Bramwell and Longson (r938) to be due to mitral stenosis, although three $\overrightarrow{0}$ had also aortic valve disease and two had auricular fibrillation.

The pulse. Provided other causes of tachycardir have been eliminated, it can be taken as a clinical rule that a pulse rate of 100 or more, persisting in spite of rest, is suggestive of cardiac embarrassment although not necessarily of organic heart disease. The pulse during normal pregnancy is often somewhat collapsing in character owing to a slight fall in the diastolic pressure rather than an increase in the systolic, and similarly, in the so-called hyperkinetic patient, capillary pulsation may be present. Extrasystoles may make themselves unpleasantly obvious for the first time 3 during pregnancy and, in fact, were present in one-half of Mackenzie's series of healthy pregnancies. On the other hand, extrasystoles which 0 have been conspicuous previously may disappear during pregnancy. Paroxysmal tachycardia, of $\frac{D}{2}$ supraventricular type, is commonly found in pregnancy and does not increase the risk. It $\mathscr{N}$ should not be treated by quinidine because of its $N$ oxytocic effect. Pregnancy itself does not give 성 rise to auricular fibrillation or flutter.

Fainting attacks. Transient giddiness during pregnancy is not uncommon and brief loss of $\frac{0}{\Phi}$ consciousness may be associated. Some of these $\stackrel{\mathscr{D}}{+}$ cases are hypotensive. Advanced aortic incom- petence may lead to fainting, and Naish (1937) is 
TABLE I

Comparison of the Physical Signs of the Normal Heart in Pregnancy with those of Mitral Valve Disease

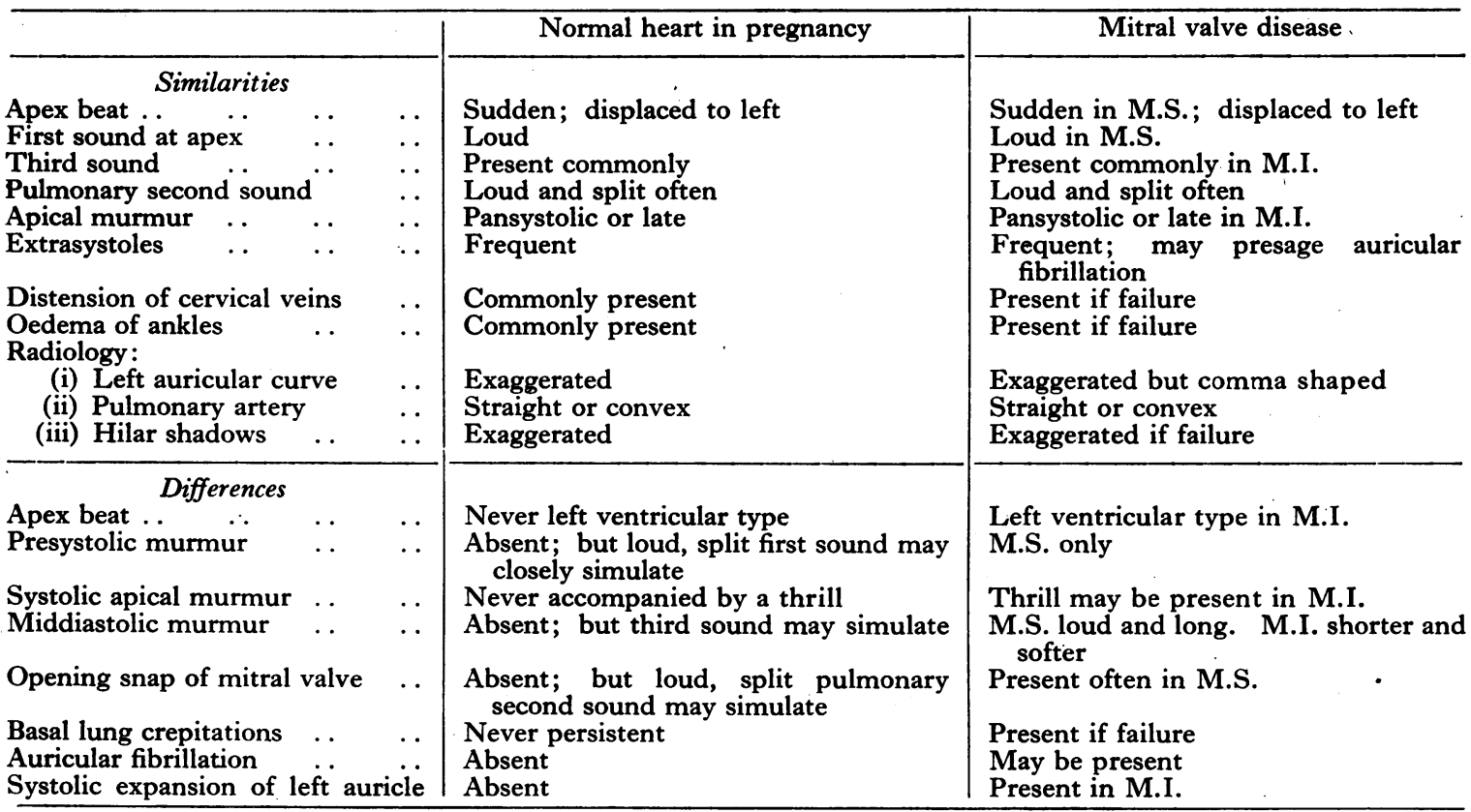

of the opinion that the fainting in these cases heralds failure.

Auscultatory cardiac signs. The physiological alteration of the auscultatory signs as a result of pregnancy often produces great difficulty in distinguishing the normal heart in pregnancy from that of mitral stenosis. This difficulty is so great that at times one cannot confidently exclude mitral stenosis during the tenure of the pregnancy (see Table I). In both conditions the first sound is loud and in pregnancy splitting of the first sound is common and may be mistaken for a short presystolic murmur. The physiological third sound is so common in pregnancy and, particularly if it is rather blurred, may closely resemble the middiastolic murmur of mitral valve disease. The pulmonary second sound is commonly accentuated and split in both pregnancy and mitral stenosis. The accentuation of it is said to be greatest during the third trimester. The systolic apical murmur which appears during pregnancy can be sufficiently long and loud to simulate mitral incompetence.

Gammeltoft (1928) originally described a murmur at the pulmonary area which has become to be considered so characteristic of pregnancy by Jensen (1938) that he refers to it as the gestatory murmur. It is best heard in the second and third intercostal spaces close to the left of the sternum and may be so loud that pericardial friction is suggested. It is louder with the patient supine and tends to become softer on deep inspiration. It is common between the fourth and fifth months and may vary strikingly from week to week. Although Landt and Benjamin (1936) are of the opinion that its presence is due to kinking of the pulmonary artery, there does not seem any convincing radiological or other evidence that this is the cause. To the author's ear the murmur sounds very like, if not identical with, that found in some cases of thyrotoxicosis. Jensen (1938) has described a thrill accompanying it but $I$ have never encountered one.

Fluoroscopy. Whether the heart hypertrophies during pregnancy is still unknown. There is disappointingly little careful evidence based on actual ventricular weights during and after pregnancy. Such specimens are, of course, very hard to obtain. Radiological evidence is equivocal but there is no doubt that the heart does appear to become a little larger radiologically during pregnancy and can closely simulate the silhouette found in mitral stenosis. Gammeltoft (1928) showed that the heart increased in both the longitudinal and transverse diameters even as early as the fourth month before pressure by the diaphragm on the heart could play a part. Later in pregnancy the displaced heart may be sufficient to move the apex beat an inch beyond the midclavicular line and up into the fourth intercostal space. Sometimes the pulmonary arc becomes 
prominent giving rise to straightening of the left border of the heart and this, coupled with the exaggerated oesophageal curve due to pressure by the left auricle which is commonly seen in pregnancy, caused Gerhardt to coin the term 'mitral shape without mitral lesion.' 'This exaggeration of the normal slight curve in the oesophagram due to the impression of the left auricle occurred in ro of I 8 cases of Hollander and Crawford (1943). They attributed it to an increase in the size of the heart as a result of the increased blood it contains, but in my experience no diagnostic difficulty arises until the heart is being pressed on from below and the exaggeration of the curve can be reduced by getting the patient to breathe in. Towards the end of normal pregnancy the hilar markings may be so extensive as to be mistaken for abnormal pulmonary congestion-a trap emphasized by Hamilton and Thomson (I94I).

The electrocardiogram. Pardee (1922) was the first to point out that pregnancy sometimes gives rise to a deep $Q$ wave and inversion of the $T$ wave in standlard lead III. This appearance may resemble posterior cardiac infarction but in pregnancy the $P$ wave in lead III is often inverted too, unlike in infarction. If any doubt exists unipolar lead VF taken from the left leg will settle the matter. Fortunately the problem rarely arisesCampbell (1947) cannot remember having seen a patient with angina become pregnant and Bramwell (1938) is of similar opinion concerning its rarity. This so-called ' $\mathrm{Q}_{3} \mathrm{~T}_{3}$ ' appearance is probably due to cardiac displacement.

\section{The Risks During and Shortly After Pregnancy}

Limitation of activity. Of recent years emphasis has shifted more and more away from the actual lesion present and towards the recognition of the great importance of judging the likely outcome during pregnancy from a simple knowledge of the degree of activity which the patient can achieve. It is one of the first duties of the cardiologist to place his patient in one of the four categories suggested by the New York Heart Association (1939). Class I consists of patients who have no limitation of activity on considerable exertion; Class II (a) have their activity slightly limited and Class II (b) greatly so; Class III patients are largely or entirely bed-ridden. The value of this classification was strikingly brought out by Jensen (1938). He collated the figures from nine different cardiac centres and found that the mortality in Classes I and II (a) was less than $\frac{1}{2}$ per cent., but in Class II (b) it rose to over 5 per cent. and in Class III it shot up to 23 per cent. Haig and Gilchrist (1949), as a result of 20 years' experience of the application of this method of classification, are enthusiastic about its great value.
However, notwithstanding the undisputed valuêi of this simple classification there is a type of patient, usually young, who although classifiablez in Class I when first seen may for the first times ever have a sudden attack of acute pulmonary.. oedema which appears to come out of the blue and unfortunately the first attack may prove fatal. She is almost always in normal rhythm and the overalle size of the heart is little, if at all, enlarged, although at autopsy the left auricle is usually found to be severely hypertrophied (Bramwell and Jones, 1944). However, the right ventricular hyper- $\infty$ trophy, which is invariably present, may be $\vec{\circ}$ confirmed by the electrocardiogram. It is in thisgroup of patients especially that routine fluoro- $\vec{\omega}$ scopy may forewarn the cardiologist of impendingo disaster. This acute pulmonary oedema is the and in Morgan Jones' (195I) series was the most important cardiac cause of death. Its treat- $N$ ment is described below. According to Bramwell and Jones (1944) a history of haemoptysis, $\stackrel{+}{+}$ especially if associated with paroxysmal dypsnoea, के implies a liability to acute pulmonary oedema.은 These attacks are apt to appear at about the middle stage of pregnancy and have been attributed to acute left auricular failure by Bramwell and Jones (1944).

Presence of failure. A history of heart failure at any time prior to pregnancy is considered many to be a contraindication to further pres. nancies and sufficient justification for interruptiog an existing one as soon as the failure has been treated adequately. Twenty-six of Bramwell's (1938) patients had congestive heart failure when first seen and of these ten died prior to or soon $\frac{\varnothing}{\varnothing}$ after confinement and four others died within the $\overrightarrow{\vec{F}}$ next six years. The French in particular are of the 3 opinion that congestive failure in pregnancy? advances much faster than otherwise (ils brûlento les étapes) but there is no convincing evidence to support this idea.

Congestive failure is a factor in about three-id quarters of deaths of patients with heart disease. A large proportion of the remainder die fromo pulmonary causes, including pulmonary oedema $₹$ and infarction, themselves a result of failure. 을 Sometimes 'cardiac exhaustion' is the only label $\square$ that one can apply-the patient becomes weak, apathetic, pale and shocked. McKeown (1945, N 1948) has produced convincing autopsy evidence. that at least some of these " acute obstetric shock' $N$ cases die as a result of unsuspected rheumatic carditis even in a heart which is not the site of aO mechanical lesion.

The 'urgency admission.' It is perhaps not surprising that it is among the urgency admissions? to hospital that the highest mortality is found; ${ }^{-}$ 14 out of 25 deaths in Bramwell's (1938) series 
were urgency admissions whereas only i I of 325 cases who had been under observation in the antenatal clinic succumbed, a striking testimony to the value of such supervision. Of Marshall's (1949) fatal cases in Belfast 46.5 per cent. occurred among the 43 emergency admissions.

The cardiac rhythm. The only common serious abnormality of rhythm is auricular fibrillation. Of Bramwell and Longson's (1938) 24 cases seven died. After carefully following up their cases they concluded that the presence of fibrillation, although undoubtedly adding considerably to the risk, did not constitute the absolute bar to pregnancy that Mackenzie (I92I) considered it to be. In fact, as Mackenzie himself said, no single sign shown by the heart itself, however abnormal it may seem, should be a bar to pregnancy.

Age and social class of mother and number and spacing of pregnancies. An important cause of breakdown is inadequate rest which accompanies pregnancy and the puerperium. Hamilton and Thomson (194I) state that after the age of 35 the risk of pregnancy rises steeply. Labour is apt to be prolonged and the lesions are usually becoming more severe. There is no doubt, too, that after the first pregnancy the risk rises steeply. It is usually accepted that an interval of at least two years is desirable between pregnancies but Hamilton and Thomson (I94I) think that a year is adequate. In so far as a child of one year needs closer attention from the mother than a child of two or more, it seems to the author that much is to be gained by waiting the longer period. Haig and Gilchrist (I949) have recently published their follow-up results of two consecutive pregnancies in 169 women. Their figures show that a woman who attains Class II (b) or III in one pregnancy will do so again in the next. Even in Classes $I$ and II (a) there is a definite downward tendency; for example, $5^{\circ}$ per cent. of those women who were Class I in the preceding pregnancy were Class II (a) in the next. Ten per cent. advanced from Class I to Class III but in each of these 12 years or more had elapsed between the two consecutive pregnancies.

The cardiac lesion and size. The commonest disease is mitral stenosis which accounts for about three-quarters of all cases. The addition of an aortic lesion to the mitral does not, in itself, influence the outlook (Harris, 1937). Although in general it is true that the larger the heart the greater the risk (Hunt, 1926), it will be remembered that in mitral stenosis fatal acute pulmonary oedema can occur associated with a heart which is little, if at all, enlarged.

Subacute bacterial endocarditis is a small but definite risk during pregnancy occurring in I per cent. of cases.

\section{Antenatal Management and Conduct of Labour and Puerperium}

The frequency with which the patient is seen antenatally will naturally vary according to the severity of her lesion and her progress, but as a rule she will be seen each month for the first six months, fortnightly for the next two months and then weekly until two weeks before the expected date of delivery, at which time she should be admitted to hospital. The strain of travelling for so many attendances is considerable, especially in winter months, and exposure to respiratory and other infections attendant upon a prolonged wait in a crowded out-patient department should be reduced to an absolute minimum. The days of attendance of the cardiologist and obstetrician should be made to coincide. At her first visit she is introduced to the almoner and the most important function of the latter is to see that sufficient help in the house is provided. She is instructed to retire to bed should a cold develop. In any but the most trivial respiratory or other infection the patient should be admitted to hospital for rest and treatment as even comparatively slight infections can precipitate failure during pregnancy (Oppel, I940).

It is difficult to lay down hard and fast rules concerning rest but at least ten hours in bed at night and a rest of two hours in the afternoon is advised. The patient is admitted to hospital for rest in bed two weeks before her expected date of delivery.

- The usual dental care, including attention to the gums, is especially important during pregnancy in view of the slight risk of subacute bacterial endocarditis. Of the usual vitamin requirements during pregnancy the vitamin B complex is particularly important in heart-failure patients. It is also important to watch for anaemia in heart patients and, if treatment is urgent, parenteral iron is preferable.

In addition to the usual routine clinical examination cardioscopy is performed at every visit. If this is omitted hilar congestion due to early heart failure will be missed.

If, in spite of these measures, heart failure supervenes, the patient should be admitted to hospital and the subsequent management then depends upon whether the failure has come on early or late in pregnancy.

There are no absolute indications to terminate pregnancy although one or two are so strong that if they are present there must be considerable justification before continuation of pregnancy is condoned. The indications are based on what has already been said above concerning the assessment of the risks involved, but for convenience they can be reconsidered as conditions which almost always 
TÁbe 2

Summary of Practical Management of Pregnant Patients in Heart failure

\begin{tabular}{|c|c|c|c|c|c|}
\hline \multirow{3}{*}{$\begin{array}{c}\begin{array}{c}\text { Stage of } \\
\text { pregnancy }\end{array} \\
\text { Up to } 14^{\text {th }} \text { week }\end{array}$} & \multirow{3}{*}{$\begin{array}{c}\begin{array}{c}\text { Degree or } \\
\text { progress of } \\
\text { failure }\end{array} \\
\text { Slight }\end{array}$} & \multicolumn{2}{|c|}{ Primipara } & \multicolumn{2}{|c|}{ Multipara } \\
\hline & & Procedure & Method & Procedure & Method \\
\hline & & $\begin{array}{l}\text { Proceed to term } \\
\text { Consider } \\
\text { valvotomy }\end{array}$ & Natural labour & $\begin{array}{c}\text { Terminate (with } \\
\text { few exceptions) }\end{array}$ & Vaginal \\
\hline & Severe & Terminate & Vaginal & Terminate & Vaginal \\
\hline \multirow{2}{*}{$\begin{array}{l}\text { From } 14 \text { th to } 36 \text { th } \\
\text { week }\end{array}$} & Improvement & $\begin{array}{l}\text { Proceed to term } \\
\text { Consider } \\
\text { valvotomy }\end{array}$ & Natural labour & $\begin{array}{l}\text { Proceed to term } \\
\text { Consider } \\
\text { valvotomy }\end{array}$ & $\begin{array}{l}\text { Natural labour } \\
\text { Consider } \\
\text { induction }\end{array}$ \\
\hline & Deterioration & $\begin{array}{c}\text { Terminate as } \\
\text { last resort }\end{array}$ & $\begin{array}{c}\text { Abdominal } \\
\text { hysterotomy }\end{array}$ & $\begin{array}{c}\text { Terminate as last } \\
\text { resort }\end{array}$ & $\begin{array}{c}\text { Abdominal } \\
\text { hysterotomy }\end{array}$ \\
\hline \multirow{2}{*}{$\begin{array}{l}\text { From 36th week } \\
\text { onwards }\end{array}$} & Improvement & Proceed to term & Natural labour & Proceed to term & $\begin{array}{l}\text { Natural labour } \\
\text { Consider induction }\end{array}$ \\
\hline & Deterioration & $\begin{array}{l}\text { Terminate } \\
\text { (rarely } \\
\text { required) }\end{array}$ & $\begin{array}{c}\text { Caesarian } \\
\text { section }\end{array}$ & $\begin{array}{l}\text { Terminate } \\
\text { (rarely } \\
\text { required) }\end{array}$ & $\begin{array}{c}\text { Caesarian } \\
\text { section }\end{array}$ \\
\hline
\end{tabular}

indicate interruption of pregnancy and those which do so less commonly.

Of recent years it has been shown that in some patients mitral valvotomy can be offered as an alternative to therapeutic abortion. Valvotomy is tolerated surprisingly well during pregnancy by both mother and foetus. In the author's view the operation is practically only indicated in those patients prone to attacks of acute pulmonary oedema. If this is the patient's first pregnancy valvotomy may be indicated at any stage except during the last few weeks, when her condition almost certainly will improve, but if the patient already has children and is in failure when first seen early in pregnancy it is probably better to terminate her as soon as the failure has been cleared up. If a multipara is so late in pregnancy that vaginal termination is not then feasible she can be considered for valvotomy (see Table 2).

The treatment of a case of acute pulmonary oedema consists of attempting to lower the pulmonary hypertension by diminishing the venous return to the heart and of improving the diastolic filling of the left ventricle by reducing the tachycardia which is usually, in part at least, of nervous origin. A clear airway must also be maintained. These objects are achieved by allaying the patient's anxiety with morphine, propping her upright in a sitting position preferably with her legs dependent over the edge of the bed (ideally in a cardiac bed), venesecting a pint rapidly or placing cuffs round the thighs and maintaining them at a pressure of
$50 \mathrm{~mm} . \mathrm{Hg}$, giving intravenously $\mathrm{I} \mathrm{mg.} \mathrm{of} \mathrm{ouabaine}$ and $0.48 \mathrm{~g}$. of theophylline ethylene-diamine. The respiratory passages are kept clear of frothy mucois $\overrightarrow{0}$ by means of a mechanical aspirator and oxygen 18 . administered by a light plastic mask (Britis̄ Oxygen Company). A regime of fluid and sodiume restriction and a mercurial diuretic is then started $\frac{2}{0}$

\section{Conditions in which Therapeutic Abortion iso Strongly Indicated}

I. Those patients with a history of paroxysma $\overline{\vec{b}}$ nocturnal dyspnoea due to acute pulmonary oedema. The alternative, however, for some patients is valvotomy. These patients often seem. deceptively well between attacks and the decision between valvotomy and termination of the pregnancy is a most difficult one and is discussed above 3

2. Patients largely or entirely bedridden as a result of heart failure (Class III of the New York Heart Association, 1939). In addition to the risko to the mother there is a strong possibility that she will not have a live baby. It is essential to treat theo heart failure before the pregnancy is terminated but unfortunately in this type of patient often theor failure only partly responds to treatment and the decision as to the optimum moment to interruptrv pregnancy is difficult and is made in close consulta -0 tion with the obstetrician. If this patient is allowed to continue pregnancy it must be realized that the mortality is nearly one in four.

3. In patients greatly limited by heart disease the mortality is about 5 per cent. (Class II (b) ofo 
the New York Heart Association). If pregnancy is far advanced when the patient is first seen it is sometimes possible to coax these patients through the remainder of their pregnancy and this may be justified when both parents are very anxious that it should be attempted.

4. However slight the heart failure is to begin with if it progresses in spite of treatment in bed termination is indicated.

\section{Conditions Calling for Serious Consideration of Termination of Pregnancy}

I. The ' urgency admission.' These patients account for one-half of the total deaths of cardiac patients during pregnancy (Bramwell, r938). The failure must, of course, be treated prior to termination.

2. A past history of failure is unfavourable but not, in the author's opinion, an absolute indication to terminate pregnancy.

3. Auricular fibrillation in itself does not constitute an absolute bar but certainly warrants serious consideration.

4. If the patient is over 35 when she first becomes pregnant she is a poor risk and after the third pregnancy in a cardiac patient the risk rises steeply whatever the age. It is especially in such patients that the availability of domestic help is of such vital importance.

\section{Failure in Early Pregnancy up to the r4th Week}

If the failure is slight and the patient is a primipara the failure should be treated in the usual manner, including the use of mercurial diuretics intramuscularly if required, and the patient allowed to proceed with the pregnancy, but if the failure is more than slight termination is the better course. If it is a multipara who is in failure then termination is best advised but an exception might be considered when the failure is slight and both parents are very anxious to have a child.

The methods of interrupting pregnancy at this stage are vaginal termination followed by contraceptive instruction or abdominal hysterotomy and sterilization at the same time.

It is essential to realize that termination must be carried out only after first treating the heart failure intensively.

\section{Failure Between the $14^{\text {th }}$ and $35^{\text {th }}$ to $3^{\text {th }}$ Week of Pregnancy}

Whether primiparae or multiparae the decision to interfere surgically is deferred until the failure is treated. If the failure improves the patient is allowed to proceed to term and valvotomy may be considered. She should be sterilized at the end of the third week of puerperium. If the failure increases in spite of treatment abdominal hysterotomy will be required but the patient is by then a very poor risk indeed. If the failure responds to treatment Caesarean section is unnecessary and, as there is a minimal mortality from this operation of I per cent., it is never justified to carry it out merely to permit sterilization at the same time.

Induction of labour has no place in the treatment of primiparas with heart disease and very little, if any, place in the treatment of multiparae.

\section{Failure from the $35^{\text {th }}$ to $3^{\text {th }}$ Week Onwards}

As it is known that from about the 36 th week her condition is very likely to improve and there is a possibility of labour being premature, the object at this stage is to try and coax the patient to term. At term, analgesia, episiotomy and, if necessary, low forceps should be employed readily. However if failure increases in spite of treatment and therefore natural labour cannot be awaited, there are only two alternatives, either induction of labour by rupture of the membranes or Caesarean section. It is the author's view that induction of labour is never preferable to Caesarean section if the patient's condition is deteriorating.

Even when Caesarean section is carried out it must be realized that the mortality rate after this operation is at least twice as high as after pelvic delivery (Gorenberg and McGleary, I94I ; Hamilton and Thomas, 194I; Mendelson, r944; Haig and Gilchrist, 1949), and there is no doubt that a policy of ' non-intervention' is being employed with increasing success and the justification for Caesarean section grows less and less. It is best reserved for those cases who are deteriorating rapidly in spite of careful treatment and who are showing no signs of going into labour (see Table 2).

Conduct of labour. If the patient reaches term in good condition she may be expected to go through labour safely. Although it is commonly believed that labour is usually short and easy in patients with heart disease this was not confirmed by Nelson and Eades (1935) nor by Mendelson (1944).

During the first stage the patient should conserve her strength by resting as much as possible and if the first stage is prolonged rest between pains should be ensured by sedatives such as chloral or pethidine. Sedation is especially important in mitral stenotics prone to attacks of pulmonary oedema.

In the second stage there is evidence that the use of the semi-recumbent position is of value prophylactically and it should certainly be used if the patient is dyspnoeic. Strong expulsive efforts should be reduced as far as possible and must be prevented by nitrous oxide and oxygen or cyclopropane and oxygen. Caudal anaesthesia has 
its advocates and episiotomy should be done without hesitation. As soon as full dilatation of the cervix has occurred forceps can be applied but their routine use is unnecessary.

The development of pulmonary oedema during delivery or a few hours post-partum is a dramatic complication, especially in mitral stenosis. It is due to over-filling of the lesser circulation with blood returning in great quantities from the placental sinuses and from the uterine sinuses after the placenta has been removed and the uterus has retracted. Treatment has been described previously. The use of a sandbag across the abdomen or application of a thick pad and binder after delivery can fulfil little useful purpose.

The puerperium and subsequently. The patient is kept in bed for at least three weeks and until all signs of failure have gone. Nearly a quarter of all fatalities occur during labour and the 24 hours following it. Lactation should be avoided only where the mother is so ill that all means must be employed to conserve her strength. As Ward (1923) has pointed out, the disturbances entailed in making up artificial feeds at night and dealing with a child made more fretful by artificial feeding may prove more exhausting than lactation.

\section{The Remote Outlook}

On first consideration it might be expected that the strain of repeated pregnancies in a woman with heart disease would ultimately decrease the efficiency of the heart. But the cardiac reserve is not a fixed quantity, amounts of which are used up until it is exhausted. Gilchrist and Murray-Lyon (1933) tried to assess the rate of progression of fatal cases of rheumatic heart disease in parous women compared with nulliparous females and males. Allowing for deaths occurring before marriageable age the average age at death was: Males, 39.3 years; nulliparae, 42.1; parous women, 42.0. Reid's (1934) figures support this contention and so do those of Jensen (1949) who states that the death rate is not increased amongst those with high parity nor by the occurrence of twin pregnancy.
BIBLIOGRAPHY
ANTHONY, A. J., and HANSEN, R. (19.33), Ztschr. f. Geburtsch v. Gynak, 105, 183.

BRAMWELL, C., and JONES, A. M. (1944), Brit. Heart f., 6, 129. BRAMWELL, C., and LONGSON, E. A. (1938), ' Heart Disease and Pregnancy,' London, Oxford Medical Publications.

BURWELL, C. S., and STRAYHORN, D. (1938), Arch. intern. Med., 62, 979.

CAMPBELL, M. (1947), Guy's Hosp. Gazette, 61, 169.

CHESLEY, L. C. (1944), Amer. F. Obs. Gyn., 48, 565.

COHEN, M. E., and THOMSON, K. L. (1936), New Eng. F. MedO 214, 905 .

COHEN, M. E., and THOMSON, K. J. (1939), F. Amer. med. Ass $\frac{\bar{\sigma}}{\mathrm{w}}$ II2, 1556.

EVANS, W. (1948), ' Cardiology,' London, Butterworth \& Co., Ltd而

GAMMELTOFT, S. A. (1928), Surg., Gyn. and Obst., 46, 382.

GILCHRIST, A. R., and MURRAY-LYON, R. M. (1933), Edivin med.. ., 40, 587 .

GORENBERG, H., and MCGLEARY, J. (1941), Amer. F. Obs $\vec{P}$ Gyn., 4I, 44.

HAIG, D. C., and GILCHRIST, A. R. (1949), Trans. Edin. Obs Soc., p. 55 .

HAMILTON, B. E., and THOMSON, K. J. (I94I), 'The Hea in Pregnancy and the Childbearing Age.' Boston, Little, Browm $\&$ Co.

HARRIS, K. (1937), Lancet, i, 677.

HARRISON, T. R. (I935), 'Failure of the Circulation' Baltimor

HOLLANDER, A. G., and CRAWFORD, J. H. (1943), Amen Heart F., 26, 364.

HUNT, G. H. (1926), Guy's Hosp. Rep., 6, r35.

JENSEN, J. (1938), “'The Heart in Pregnancy,' London, $H_{0}$ Kimpton.

JENSEN, J. (1949), Mod. Concepts of Cardiovasc. Dis., 18, 29.

LANDT, H., and BENJAMIN, J. E. (1936), Amer. Heart F., I2, 592.

MACKENZIE, J. (1921), ' Heart Disease and Pregnancy,' Londorn Henry Frowde and Hodder \& Stoughton.

MARSHALL, R. (1949), 'Heart Disease and Pregnancy: the Clinical Aspect,' paper read before British Cardiac Society June.

MCKEOWN, F. (1945), Ulster med. F., 14, 97.

MCKEOWN, F. (1948), f. Obst. Gyn. Brit. Emp., 55, 50.

MENDELSON, C. L. (1944), Amer. F. Obst. Gyn., 48, 329.

MORGAN JONES, A. (195I), 'Heart Disease in Pregnancy London, Harvey \& Blythe, Ltd.

NAISH, F. C. (1937), F. Obst. Gyn. Brit. Emp., 44, 659.

NELSON, H. B., and EADES, F. S. (1935), New Eng. F. Med 213, 1057.

NEW YORK HEART ASSOCIATION (1939), 'Diagnosis of Diseases of the Heart,' fourth edition, New York.

OPPEL, T. W. (1940), Amer. F. Obst. Gyn., 39, 24.

PARDEE, H. E. B. (1922), Ibid., 3, 620.

REID, W. D. (1934), F. Amer. med. Ass., ro3, 889.

STANDER, H. J., and CADDEN, J. F. (1932), Amer. 7. Obs Gyn., 24, 13. THOMSON, K. J., and COHEN, M. E. (1938), Surg. Gyn. and
Obst., 66, $50 \mathrm{I}$.

THOMSON, K. J., HIRSHEIMER, A., GIBSON, J. G., and and EVÁNS, W. A. (1938), Amer. F. Obst. Gyn., 36, 48.

WARD, E. (1923), Lancet, ii, 557.

\title{
BACK NUMBERS OF THE POSTGRADUATE MEDICAL JOURNAL
}

\author{
If any subscribers have copies, in good condition, of JANUARY, FEBRUARY and \\ MARCH r953, the Fellowship of Postgraduate Medicine, 60 Portland Place, London, \\ W.r, will be glad to purchase them.
}

